\title{
The significance of carbon dioxide and methane measurements in the estimation of heat production in cattle
}

\author{
BY J. A. MCLEAN \\ Hannah Research Institute, Ayr KA6 5HL \\ (Received 25 November 1985 - Accepted 10 January 1986)
}

\begin{abstract}
1. Records of metabolic measurements on cattle by open-circuit indirect calorimetry have been examined to determine the practical significance in the calculation of heat production of including measurements of carbon dioxide and methane in addition to the measurement of oxygen.

2. It was found that the combined effects of $\mathrm{CO}_{2}$ and $\mathrm{CH}_{4}$ made only a small contribution to the total estimation of heat production which could be calculated with approximately $\pm 1 \%$ accuracy from analysis of $\mathrm{O}_{2}$ alone.
\end{abstract}

In all open-circuit systems for measuring respiratory gaseous exchange (face-masks, head-hoods or respiration chambers) it is convenient to compute metabolic rate $(\dot{M})$ from the directly measured quantities (flow-rate and gas concentrations).

Using the energy factors recommended by Brouwer (1965), the author derived an equation relating $\dot{M}(\mathrm{~kW})$ to exhaust air flow-rate $\left(\dot{V}_{\mathrm{E}} ; 1 / \mathrm{s} ;\right.$ standard temperature and pressure of dry gas) and gas concentration differences (McLean, 1972).

$$
\dot{M}=\dot{V}_{\mathrm{E}}\left(-20 \cdot 47 \Delta F_{\mathrm{O}_{2}}+0 \cdot 73 \Delta F_{\mathrm{CO}_{2}}-6 \cdot 46 \Delta F_{\mathrm{CH}_{4}}\right)-5 \cdot 99 \dot{N},
$$

where $\Delta F_{\mathrm{O}_{2}}, \Delta F_{\mathrm{CO}_{2}}$ and $\Delta F_{\mathrm{CH}_{4}}$ are gas concentration differences (exhaust air minus inlet air) and $\dot{N}$ is the rate of urinary nitrogen production $(\mathrm{g} / \mathrm{s})$.

In a later publication (McLean \& Watts, 1976), a differential term was included consisting of the volume of the apparatus, $V$ (l) multiplied by the rates of change of gas concentrations $(\mathrm{d}(\Delta F) / \mathrm{d} t ; / \mathrm{s})$ :

$$
\dot{M}=\left(\dot{V}_{\mathrm{E}}+V \mathrm{~d} / \mathrm{d} t\right)\left(-20 \cdot 47 \Delta F_{\mathrm{O}_{2}}+0.73 \Delta F_{\mathrm{CO}_{2}}-6.46 \Delta F_{\mathrm{CH}_{4}}\right)-5.99 \dot{N} .
$$

Over a prolonged period of successive measurements the differential term has no effect on the mean value of $\dot{M}$ since $\Sigma V \mathrm{~d}(\Delta F) / \mathrm{d} t$, tends towards zero; the only effect of including it is to sharpen the speed of response of the calculated value of $\dot{M}$ to changing gas concentrations. This is important in large respiration chambers where the fresh-air ventilation rate per min is small compared with the volume of the chamber, and gas concentrations may take many minutes or even hours to attain equilibrium levels. However, with face masks, where the dead space is small, inclusion of the differential term is often of little advantage.

It was suggested (McLean, 1972) that, compared with the term involving oxygen, those involving carbon dioxide and methane were relatively small and approximately equal and opposite; but no direct evidence was available to support this. In the intervening period we have accumulated a sufficient bank of data from metabolic measurements on cattle to test the assertion.

\section{METHODS}

The results summarized here are taken from two series of experiments (McLean et al. $1983 a, b)$ on cattle subjected to various fluctuating thermal environments. The animals received a balanced daily maintenance ration $(160 \mathrm{~g}$ protein $/ \mathrm{kg}$ dry matter; $18 \mathrm{~g}$ ration $/ \mathrm{kg}$ 

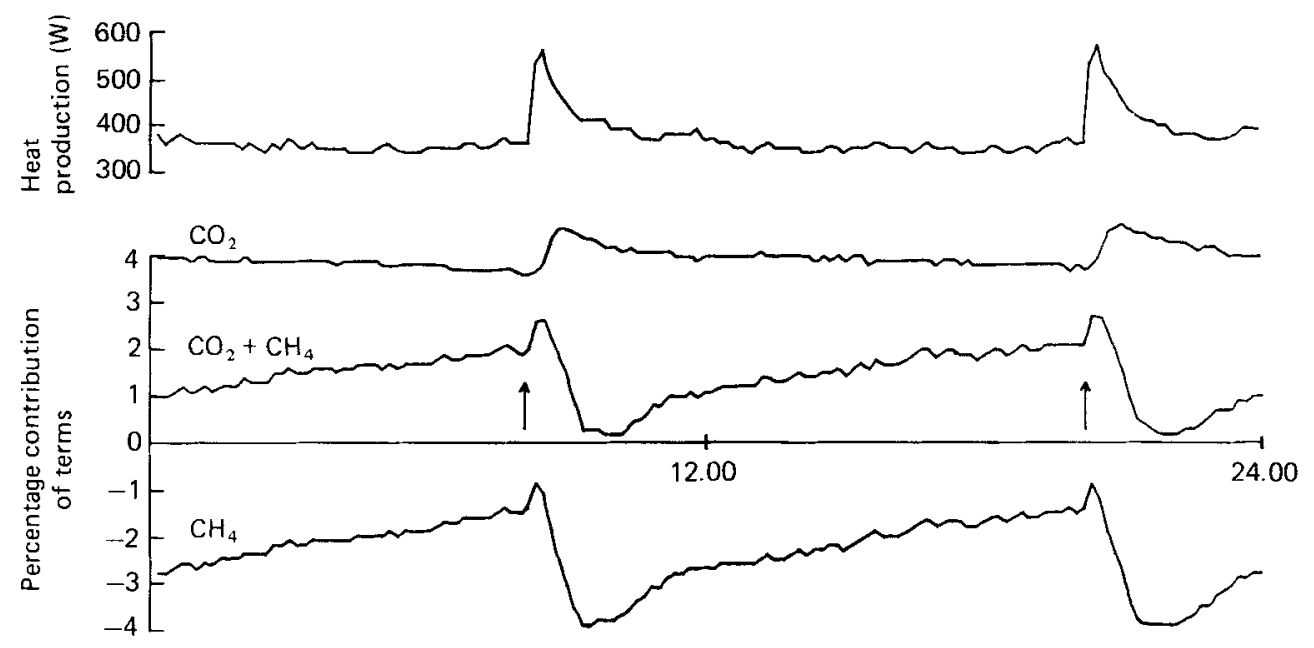

Time of day (hours)

Fig. 1. The daily variation in heat production $(M)$ of cattle and in the percentage contributions in the equation for $\dot{M}$, of terms involving carbon dioxide, methane and their sum $\left(\mathrm{CO}_{2}+\mathrm{CH}_{4}\right)$. $\uparrow$, Times of feeding.

body-weight per d) offered in two equal halves at $12 \mathrm{~h}$ intervals. Gas concentrations were measured at regular intervals, $\tau$, of $10 \mathrm{~min}$; the differential terms for the $n^{\text {th }}$ and $(n+1)^{\text {th }}$ measurements being calculated as $\left[\Delta F_{n+1}-\Delta F_{n}\right] / \tau$. The differential terms were included for $\mathrm{O}_{2}$ and $\mathrm{CO}_{2}$ but not for $\mathrm{CH}_{4}$. This was because the animals had an irregular pattern of $\mathrm{CH}_{4}$ exhalation and inclusion of a differential term for $\mathrm{CH}_{4}$ would reflect these irregularities as much as the true rate of methanogenesis. The rate of urinary $\mathrm{N}$ excretion was not measured, but was assumed to contribute $-1 \%$ to the value of $\dot{M}$ (McLean, 1972).

\section{RESULTS AND DISCUSSION}

From a total of 8922 individual estimates of $\dot{M}$ the highest ever recorded contribution of the $\mathrm{CO}_{2}$ term was $6.47 \%$ and the lowest $2.42 \%$; for $\mathrm{CH}_{4}$ the highest and lowest contributions were -0.05 and $-6.83 \%$ respectively.

When these values are arranged according to the time at which they were recorded they show remarkable consistency. Fig. 1 shows plots according to time of day of the mean values for $\dot{M}$ and the percentage contributions to $\dot{M}$ of the $\mathrm{CO}_{2}$ term, the $\mathrm{CH}_{4}$ term and their sum. In each graph each of the 144 points plotted represents the mean of thirty-five to sixty-eight measurements made at that time of day. The mean standard deviation of the percentage contribution to $\dot{M}$ at any specified time was $0.28 \%$ for $\mathrm{CO}_{2}$ and $0.60 \%$ for $\mathrm{CH}_{4}$. The contribution of the $\mathrm{CO}_{2}$ term was nearly stable over the $24 \mathrm{~h}$ period except for slight peaks after feeding, its mean value was $3.78 \%$. The absolute value of the $\mathrm{CH}_{4}$ contribution showed a sharp increment following feeding and thereafter a slow steady decline until the next feed; the overall mean level of the $\mathrm{CH}_{4}$ term was $-2.57 \%$. During the act of eating (for approximately $25 \mathrm{~min}$ ) there was a small diminution in the absolute value of the $\mathrm{CH}_{4}$ contribution. This probably reflects inhibition of methanogenesis in the rumen due to $\mathrm{O}_{2}$ swallowed whilst feeding, which has been demonstrated by Hillman et al. (1985).

The combined contribution of the $\mathrm{CO}_{2}$ and $\mathrm{CH}_{4}$ terms fluctuated between 0.1 and $2.5 \%$ with a mean value of $1.21 \%$. In practice this is largely offset by the assumed contribution of $-1 \%$ from the urinary $\mathrm{N}$ term. These results confirm that $\dot{M}$ for cattle may be calculated 
at any time with approximately $\pm 1 \%$ accuracy from the $\mathrm{O}_{2}$ term alone. The residual $+0.21 \%$ contribution of the combined $\mathrm{CO}_{2}, \mathrm{CH}_{4}$ and urinary $\mathrm{N}$ terms can be accommodated by a corresponding adjustment to the coefficient for $\mathrm{O}_{2}$, giving the formula

$$
\dot{M}=-20 \cdot 5\left(\dot{V}_{\mathrm{E}}+V \mathrm{~d} / \mathrm{d} t\right) \Delta F_{\mathrm{O}_{2}} \text {. }
$$

It must be emphasized that although this formula gives an accurate estimation of heat production, the quantity $-\left(\dot{V}_{\mathrm{E}}+V \mathrm{~d} / \mathrm{d} t\right) \Delta F_{\mathrm{O}_{2}}$ is not to be confused with $\mathrm{O}_{2}$ consumption. $\mathrm{O}_{2}$ consumption can only be estimated accurately if the other respiratory gases are measured (Otis, 1964; Maxfield \& Smith, 1967; McLean, 1972).

\section{REFERENCES}

Brouwer, E. (1965). In Energy Metabolism, pp. 441-443 [K. L. Blaxter, editor]. Proceedings of 3rd Symposium of Energy Metabolism. London: Academic Press.

Hillman, K., Lloyd, D. \& Williams, A. G. (1985). Current Microbiology 12, 335-340.

McLean, J. A. (1972). British Journal of Nutrition 27, 597-600.

McLean, J. A., Downie, A. J., Jones, C. D. R., Stombaugh, D. P. \& Glasbey, C. A. (1983a). Journal of Agricultural Science, Cambridge 100, 305-314.

McLean, J. A., Stombaugh, D. P., Downie, A. J. \& Glasbey, C. A. (1983b). Journal of Agricultural Science, Cambridge 100, 315-322.

McLean, J. A. \& Watts, P. R. (1976). Journal of Applied Physiology 40, 827-831.

Maxfield, M. E. \& Smith, P. E. (1967). Human Factors 9, 587-594.

Otis, A. B. (1964). In Handbook of Physiology, vol. 1, Sect. 3, pp. 681-698 [W. O. Fenn and H. Rahn, editors]. Washington: The American Physiological Society. 